\title{
Dietary changes in obese patients undergoing gastric bypass or lifestyle intervention: a clinical trial
}

\author{
Line K. Johnson $^{1,2 *}$, Lene F. Andersen ${ }^{3}$, Dag Hofs $\varnothing^{1}$, Erlend T. Aasheim ${ }^{1,4}$, Kirsten B. Holven ${ }^{3}$, \\ Rune Sandbu ${ }^{1}$, Jo Røislien ${ }^{1,5}$ and Jøran Hjelmesæth ${ }^{1}$ \\ ${ }^{1}$ Morbid Obesity Centre, Vestfold Hospital Trust, Box 2168, 3103 Tønsberg, Norway \\ ${ }^{2}$ Norwegian Resource Centre for Women's Health, Oslo University Hospital Rikshospitalet, Oslo, Norway \\ ${ }^{3}$ Department of Nutrition, Institute of Basic Medical Sciences, University of Oslo, Oslo, Norway \\ ${ }^{4}$ Department of Public Health and Primary Care, University of Cambridge, Cambridge, UK \\ ${ }^{5}$ Department of Biostatistics, Institute of Basic Medical Sciences, University of Oslo, Oslo, Norway \\ (Submitted 28 May 2012 - Final revision received 9 August 2012 - Accepted 9 September 2012 - First published online 30 October 2012)
}

\section{Abstract}

We compared changes in the dietary patterns of morbidly obese patients undergoing either laparoscopic gastric bypass surgery or a comprehensive lifestyle intervention programme. The present 1-year non-randomised controlled trial included fifty-four patients in the lifestyle group and seventy-two in the surgery group. Dietary intake was assessed by a validated FFQ. ANCOVA was used to adjust for betweengroup differences in sex, age, baseline BMI and baseline values of the dependent variables. Intakes of food groups and nutrients did not differ significantly between the intervention groups at baseline. At 1-year follow-up, the lifestyle group had a significantly higher daily intake of fruits and vegetables (561 (SD 198) $v$. 441 (SD 213) g, $P=0.002$ ), whole grains (63 (SD 24) $v$. 49 (SD 16) g, $P<0 \cdot 001)$ and fibre (28 (SD 6) v. 22 (SD 6) g, $P<0.001$ ) than the surgery group and a lower percentage of total energy intake of saturated fat (12 (SD 3 ) $v$. 14 (SD 3) \%, $P<0 \cdot 001$ ). The intake of red meat declined significantly within both groups, vegetables and fish intake were reduced significantly in the surgery group and added sugar was reduced significantly in the lifestyle group. The lifestyle patients improved their dietary patterns significantly (compared with the surgery group), increasing their intake of vegetables, whole grains and fibre and reducing their percentage intake of saturated fat (ANCOVA, all $P<0 \cdot 001$ ). In conclusion, lifestyle intervention was associated with more favourable dietary 1-year changes than gastric bypass surgery in morbidly obese patients, as measured by intake of vegetables, whole grains, fibre and saturated fat.

Key words: Morbid obesity: Gastric bypass: Lifestyle intervention programmes: Dietary intake patterns

People with severe obesity are at high risk of developing CHD, hypertension, type 2 diabetes and some forms of cancer $^{(1,2)}$. Obesity is also associated with impaired quality of life ${ }^{(3)}$ and premature mortality ${ }^{(2,4)}$.

Bariatric surgery can lead to significant and sustained weight loss as well as decreased morbidity and mortality ${ }^{(5-7)}$. However, due to surgery-related costs and adverse effects, non-surgical lifestyle modification remains the cornerstone of obesity treatment. Although no dietary strategy has yet been established as superior in terms of long-term weight loss maintenance ${ }^{(8-10)}$, intake of specific food groups, such as vegetables, whole grains, fruits, nuts and yoghurt, has been shown to be inversely associated with weight gain ${ }^{(11)}$. A diet with a limited total- and saturated fat content, rich in fruits, vegetables and low-fat dairy products, may reduce the risk of developing stroke and $\mathrm{CHD}^{(12,13)}$. Intake of fruits, berries, vegetables and whole-grain foods is associated with reduced risk of several cancer forms, while intake of red meat may increase cancer risk and mortality ${ }^{(14-16)}$. Likewise, a diet which has $<30 \%$ of total energy (E) intake from fat, $<10 \mathrm{E} \%$ from saturated fat and is rich in fibre and wholegrain foods, is associated with reduced risk of developing type 2 diabetes ${ }^{(17,18)}$.

The present dietary recommendations emphasise food groups rather than nutrients, as food-based dietary guidelines (FBDG) are thought to be easier for the general population to implement ${ }^{(19,20)}$. These guidelines emphasise a high intake of fruits, vegetables and whole grains and a limited intake of processed and energy-dense foods. By implementing these guidelines, dietary intake of complex carbohydrates (fibre), antioxidants, vitamins and minerals will increase, while intake of saturated fat will diminish ${ }^{(19,20)}$.

Abbreviation: FBDG, food-based dietary guidelines.

*Corresponding author: L. K. Johnson, fax + 47 33343991, email line.kristin.johnson@siv.no 
Bariatric surgery results in a more pronounced weight loss than conventional lifestyle intervention, mainly because of the former's greater reduction in energy intake ${ }^{(21)}$. Previous studies have focused on the effect of bariatric surgery on nutrient intake ${ }^{(22,23)}$, percentage energy distribution and potential avoidance of fatty or sweet foods ${ }^{(24)}$, but few studies have assessed the impact of gastric bypass surgery on intake of food groups in the context of recent FBDG. We therefore compared changes in the intakes of specified food groups and energy-yielding nutrients in patients undergoing either gastric bypass surgery or intensive lifestyle intervention during a 1 -year non-randomised clinical intervention trial.

\section{Methods}

\section{Study design and setting}

The study was a pre-planned per protocol analysis of dietary changes in a population of morbidly obese patients (BMI $\geq 40$ or $35 \cdot 0-39.9 \mathrm{~kg} / \mathrm{m}^{2}$ combined with at least one weight-related co-morbidity) ${ }^{(25)}$ who participated in the nonrandomised controlled morbid obesity treatment, bariatric surgery $v$. intensive lifestyle intervention (MOBIL) study (ClinicalTrials.gov: NCT00273104) ${ }^{(26,27)}$. The present study was conducted according to the guidelines laid down in the Declaration of Helsinki, and all procedures involving human subjects were approved by the Regional Ethics Committee for Medical Research in South East Norway. Written informed consent was obtained from all participants.

\section{Participants}

Of the 146 patients enrolled, a total of 139 (sixty-three in the intensive lifestyle intervention group and seventy-six in the gastric bypass surgery group) completed the MOBIL study ${ }^{(27)}$. After the exclusion of thirteen patients who declined to undergo dietary interviews (nine at baseline and four after intervention),
126 patients (fifty-four in the lifestyle group and seventy-two in the surgery group) were included in the analysis (Fig. 1). The thirteen excluded patients did not differ significantly from the remaining 126 patients in terms of age $(P=0.995)$, sex ( $P=0.593)$ or BMI $(P=0.385)$ (data not shown).

\section{Dietary data}

Dietary intake was assessed using a validated $\mathrm{FFQ}^{(28)}$. The FFQ is designed to measure the daily habitual food intake of the adult population in Norway and is suitable for estimating the intake of a variety of macro- and micronutrients, including intake from dietary supplements ${ }^{(29)}$. The FFQ was implemented through structured dietary interviews, both at baseline and at 1 year after the start of intervention. The interviews lasted between 1 and $2 \mathrm{~h}$ and were conducted by registered dietitians. The FFQ includes 180 food items and courses, grouped together according to the typical Norwegian meal pattern. Patients were asked to describe their dietary habits during the previous year and report their intake (frequency and amount) of various food items (per d, week or month). Units (e.g. slices and pieces) and household measures were used to help patients estimate portion sizes. The questionnaires were scanned (Teleform 10.0; Cardiff Software, Inc.) and the daily intake of foods, energy and nutrients were calculated using software (KBS 6.0; developed at the Institute of Basic Medical Sciences, Department of Nutrition, University of Oslo) based on the data from the Norwegian food composition table (Norwegian Nutrition Council, 1995).

\section{Interventions}

Treatment allocation was made as a joint decision between the patient and the physician. Patients allocated to surgery were given recommendations by registered dietitians regarding pre- and post-operative changes in dietary intake. Pre-operatively, patients followed a low-energy diet

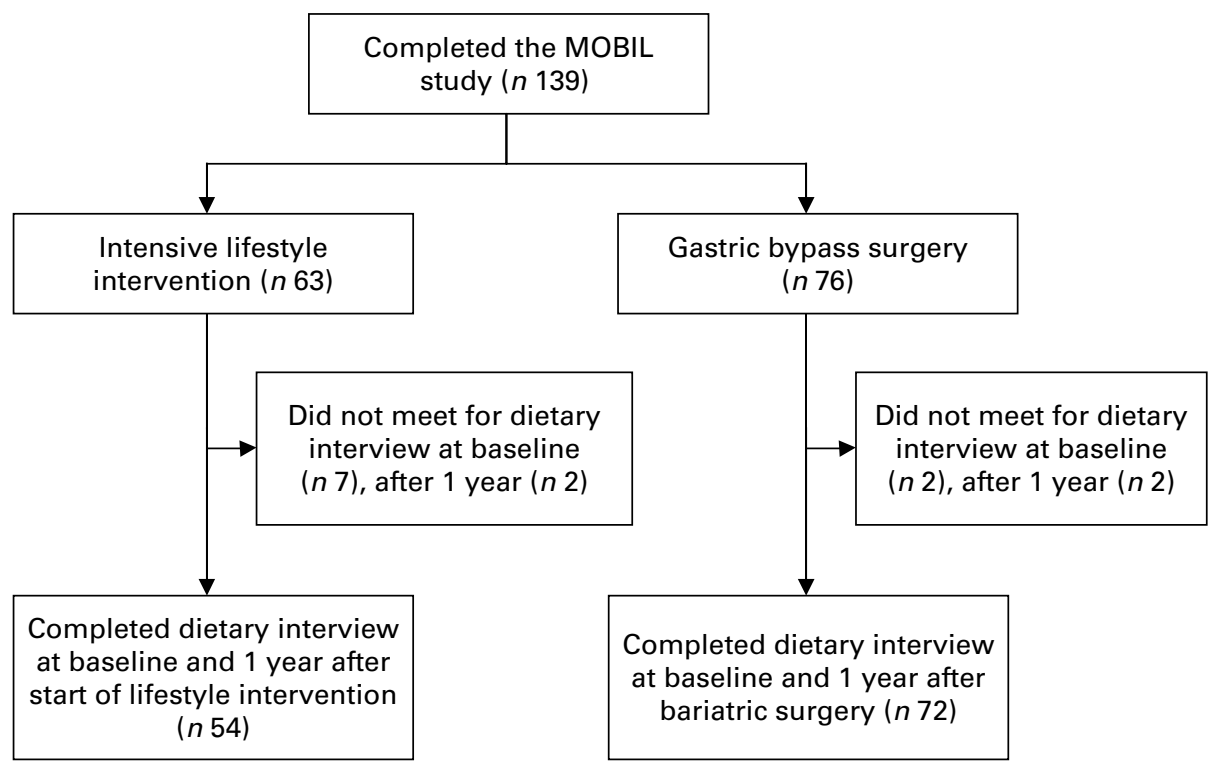

Fig. 1. Study flow. MOBIL, non-randomised controlled morbid obesity treatment, bariatric surgery $v$. intensive lifestyle intervention. 
$(3766 \mathrm{~kJ} / \mathrm{d}(900 \mathrm{kcal} / \mathrm{d}))$ for 3-6 weeks in order to reduce liver size and abdominal fat content. Roux-en-Y gastric bypass surgery was performed laparoscopically. The gastric pouch was approximately $25 \mathrm{ml}$ and the median intestinal limb lengths were as follows: alimentary limb 120 (range $80-250$ ) cm, biliopancreatic limb 100 (range 50-170) cm and common channel, variable length $^{(27)}$. With a view of preventing gastrointestinal discomfort after bariatric surgery, patients were recommended to eat small frequent meals rich in protein and fibre, to chew thoroughly and slowly and to take fluids separately from meals. Patients were informed that intake of some food types shortly after surgery could provoke postprandial discomfort; examples given were of foods with a high-fat and/or sugar content, carbonated beverages, soft 'doughy' bread, pasta, rice, alcohol, whole meat and the skin and fibres in some fruits and vegetables. To maintain weight loss and improvements in health, the importance of implementing a persistent diet in accordance with present guidelines (i.e. a varied diet with plenty of vegetables, fruits and berries, whole-grain products and fish and limited amounts of saturated fat and sugar) was emphasised. In the first year after surgery, dietary advice was given by dietitians during four consecutive group sessions and individually if needed $^{(27)}$. All patients were prescribed a standardised set of post-operative supplements consisting of a multivitamin/mineral formulation (vitamin content: $500 \mu \mathrm{g} \mathrm{A} ; 1.4 \mathrm{mg} \mathrm{B}_{1} ; 1.6 \mathrm{mg} \mathrm{B}_{2} ; 2 \mathrm{mg}$ $\mathrm{B}_{6} ; 200 \mu \mathrm{g}$ folate; $1 \mu \mathrm{g} \mathrm{B} \mathrm{B}_{12} ; 60 \mathrm{mg} \mathrm{C} ; 5 \mu \mathrm{g} \mathrm{D}$; and $10 \mathrm{mg} \mathrm{E}$ (Collett Kostpluss; Axellus)); vitamin D/Ca $(20 \mu \mathrm{g} \mathrm{D} / 1000 \mathrm{mg}$ calcium carbonate (Calcigran forte; Nycomed Pharma), Fe (65 mg ferrous sulphate, $130 \mathrm{mg}$ in women (Ferromax; Weifa)) and fish oil supplements $(10 \mu \mathrm{g} \mathrm{D}, 250 \mu \mathrm{g}$ A and $10 \mathrm{mg}$ E (Møllers Dobbel; Axellus). Vitamin $\mathrm{B}_{12}$ was given intramuscularly every 3 months (1 mg cyanocobalamine (Betolvex; Actavis)) ${ }^{(30)}$.

Patients in the lifestyle group attended a 1-year lifestyle programme at a rehabilitation centre for morbidly obese persons (Evjeklinikken, Norway). The programme comprised of four intermittent stays at the centre, one lasting 4 weeks and three lasting 1 week (total, 7 weeks) ${ }^{(27)}$. Patients had both individual consultations and group sessions with a team of health professionals, which included a medical doctor, registered dietitian, physiotherapist and nurse. Six meals were served per $\mathrm{d}$; four main meals and two snacks. Meals were prepared in accordance with the dietary recommendations from the Norwegian National Council of Nutrition (recommended distribution of energy intake: protein $10-20 \%$, fat $<30 \%$, saturated fat $<10 \%$, carbohydrate $50-60 \%$ and added sugar $<10 \%)^{(31)}$. The nutritional information given to patients was also based on these recommendations, with similar dietary advice also given to the surgery patients. Patients were encouraged to practice their newly formed lifestyle habits at home and to visit their general practitioner regularly in order to monitor their weight. The patients were also contacted by telephone at every 2 weeks. The aim of treatment was $10 \%$ weight loss or more.

\section{Outcome variables}

The primary outcomes are expressed as changes in daily intake of various food groups from baseline to follow-up.
The following food groups were assessed: fruits, vegetables, whole grains and fish and red meat. Red meat is given as cooked meat (750 g raw meat equals $500 \mathrm{~g}$ cooked meat ${ }^{(15)}$. Changes in the intake of dairy products (milk, cheese and yoghurt) were also assessed.

In addition, changes in the intake of total energy, fibre and the percentage distribution of the energy-yielding nutrients, i.e. fats (total, saturated, monounsaturated and polyunsaturated fat), carbohydrates and proteins, were assessed.

\section{Statistical analyses}

Data are given as means and standard deviations, mean (95\% CI), or proportion (\%) unless stated otherwise. Differences between groups were analysed using independent samples $t$ test for continuous data and Fisher's exact test for categorical data. Within-group changes were assessed with paired samples $t$ test. Between-group changes of food group intakes and nutrients were assessed using ANCOVA, with adjustments for sex, age, baseline BMI and baseline values of the dependent variables.

A 5\% statistical significance level was used. All analyses were implemented in SPSS 16.0 (SPSS).

\section{Results}

The seventy-two patients who underwent gastric bypass surgery were on average 4 years younger and $13 \mathrm{~kg}$ heavier than the fifty-four subjects who underwent lifestyle intervention (Table 1). The average weight loss at 1 year after the start of the intervention was $30 \%$ in the surgery group and $8 \%$ in the lifestyle group ${ }^{(27)}$.

The daily intake of various food groups did not differ significantly between the treatment groups at baseline (Table 2). A total of thirty-one (57\%) patients in the lifestyle group and thirty-five $(49 \%)$ in the surgery group $(P=0.370)$ had a daily intake below the FBDG of $\geq 500 \mathrm{~g} / \mathrm{d}$ of fruits and vegetables $^{(20)}$. A total of thirty-eight (70\%) subjects in the lifestyle group and forty (56\%) in the surgery group $(P=0.099)$ had a weekly intake of red meat above the FBDG of $<500 \mathrm{~g} /$ week.

\section{Food intake at follow-up}

The daily food group intakes at 1 year after the start of the intervention are shown in the columns on the right-hand side of Table 2 . The surgery group had a significantly lower intake of fruits and vegetables, mainly explained by a lower intake of vegetables. Surgically treated patients also had a significantly lower intake of whole grains compared with the lifestyle group. As compared with the lifestyle group, a larger proportion of patients from the surgical group had daily intakes below the FBDG for fruit and vegetables (69 v. 44\%, $P=0.006$

). The proportion of patients with a weekly intake of red meat above the FBDG $(<500 \mathrm{~g} /$ week $)$ did not differ significantly between the groups ( $22 v .28 \%, P=0.533$ ).

At follow-up, the lifestyle group tended to have a higher intake of dairy products in general and a significantly higher 
Table 1. Demographic and anthropometric baseline characteristics of the 126 morbidly obese patients who underwent either gastric bypass surgery or intensive lifestyle intervention

(Mean values and standard deviations; number of patients and percentages)

\begin{tabular}{|c|c|c|c|c|c|}
\hline & \multicolumn{2}{|c|}{$\begin{array}{l}\text { Lifestyle } \\
\text { intervention } \\
(n 54)\end{array}$} & \multicolumn{2}{|c|}{$\begin{array}{c}\text { Gastric } \\
\text { bypass } \\
\text { surgery } \\
(n 72)\end{array}$} & \multirow[b]{2}{*}{$P^{\star}$} \\
\hline & $n$ & $\%$ & $n$ & $\%$ & \\
\hline Age (years) & \multirow{2}{*}{\multicolumn{2}{|c|}{$46 \cdot 8$}} & & & 0.034 \\
\hline Mean & & & \multicolumn{2}{|c|}{$42 \cdot 6$} & \\
\hline SD & \multicolumn{2}{|c|}{11} & \multicolumn{2}{|c|}{11} & \\
\hline Sex (female) & 38 & 70 & 50 & 69 & 0.999 \\
\hline Education $\geq 13$ years (yes) & 43 & 81 & 53 & 74 & 0.394 \\
\hline Employment (yes) & 37 & 69 & 38 & 53 & 0.099 \\
\hline Caucasian (yes) & 53 & 98 & 70 & 97 & 0.999 \\
\hline Current smoker (yes) & 18 & 33 & 20 & 28 & 0.559 \\
\hline Weight $(\mathrm{kg})$ & & & & & 0.001 \\
\hline Mean & \multicolumn{2}{|c|}{123} & \multicolumn{2}{|c|}{136} & \\
\hline SD & \multicolumn{2}{|c|}{19} & \multicolumn{2}{|c|}{21} & \\
\hline BMI $\left(\mathrm{kg} / \mathrm{m}^{2}\right)$ & & & & & $<0.001$ \\
\hline Mean & \multicolumn{2}{|c|}{42.6} & \multicolumn{2}{|c|}{$46 \cdot 2$} & \\
\hline SD & \multicolumn{2}{|c|}{$5 \cdot 0$} & \multicolumn{2}{|c|}{5.9} & \\
\hline Waist $(\mathrm{cm})$ & & & & & 0.006 \\
\hline Mean & \multicolumn{2}{|c|}{129} & \multicolumn{2}{|c|}{136} & \\
\hline SD & \multicolumn{2}{|c|}{12} & \multicolumn{2}{|c|}{13} & \\
\hline
\end{tabular}

*Independent samples $t$ test or Fisher's exact test as appropriate.

intake of yoghurt in particular, as compared with the surgery group (Table 2).

\section{Changes in dietary patterns}

The changes in daily intakes of selected food groups are illustrated in Fig. 2. Vegetable intake was reduced by approximately $25 \%$ in the surgery group and tended to increase in the lifestyle group (between-group difference, $P<0 \cdot 001$ ).

Intake of whole grains did not change significantly in either group (between-group difference, $P<0.001$ ). Intakes of red meat decreased significantly in both intervention groups with no significant between-group difference $(P=0.088)$. Fish intake tended to decrease in the lifestyle group and decreased significantly in the surgery group, with no significant between-group difference $(P=0.094)$. Intake of nuts did not change significantly in either group.

\section{Nutrients and energy}

There were no significant differences in the intakes of energy and energy-yielding nutrients in the two treatment groups at baseline (Table 3). After 1 year, patients in the surgery group had a significantly lower total energy intake than patients in the lifestyle group. In contrast, the percentages of energy intake from total, saturated and monounsaturated fat were significantly lower in the lifestyle group than they were in the surgery group (Table 3 ).

The proportion of patients who reported $<30 \%$ of energy intake from fat increased from 9 to $44 \%$ in the lifestyle group and from 10 to $18 \%$ in the surgery group $(P=0.002$; Fisher's exact test). Furthermore, the proportion of patients who had $<10 \%$ of energy intake from saturated fat increased from 2 to $22 \%$ in the lifestyle group and from 3 to $4 \%$ in the surgery group $(P=0 \cdot 004$; Fisher's exact test).

Fibre intake was not significantly different between the groups at baseline. At follow-up, the surgery group reported a significantly lower fibre intake than the lifestyle group (Table 3).

At baseline, $37 \%$ of patients in the lifestyle group and $36 \%$ of the patients in the surgery group had a fibre intake below the recommended intake ( $\geq 25 \mathrm{~g} / \mathrm{d}$ ). At follow-up, the corresponding figures were 30 and $68 \%$, respectively $(P<0.001$; Fisher's exact test).

Within-group changes for percentage energy intake from various nutrients are illustrated in Fig. 3. Compared with the surgery group, patients in the lifestyle group reported significantly greater reductions in percentage energy intake from total, saturated, mono- and polyunsaturated fat. Only the lifestyle group increased their percentage energy intake from carbohydrates (between-group difference, $P<0 \cdot 001$ ).

Both groups increased their percentage of energy intake from protein, with no significant between-group difference $(P=0.588)$.

Table 2. Daily intake of various food groups at baseline and at 1 year after start of either intensive lifestyle intervention or gastric bypass surgery (Mean values and standard deviations)

\begin{tabular}{|c|c|c|c|c|c|c|c|c|c|c|c|}
\hline \multirow[b]{3}{*}{ Food group (g/d) } & \multirow{3}{*}{$\begin{array}{c}\text { Food-based dietary } \\
\text { guidelines } t\end{array}$} & \multicolumn{5}{|c|}{ Baseline } & \multicolumn{5}{|c|}{ 1-year follow-up } \\
\hline & & \multicolumn{2}{|c|}{$\begin{array}{l}\text { Lifestyle } \\
\text { (n 54) }\end{array}$} & \multicolumn{2}{|c|}{$\begin{array}{l}\text { Surgery } \\
(n 72)\end{array}$} & \multirow[b]{2}{*}{$P^{*}$} & \multicolumn{2}{|c|}{$\begin{array}{l}\text { Lifestyle } \\
\text { ( } n 54)\end{array}$} & \multicolumn{2}{|c|}{$\begin{array}{l}\text { Surgery } \\
(n 72)\end{array}$} & \multirow[b]{2}{*}{$P^{*}$} \\
\hline & & Mean & SD & Mean & SD & & Mean & SD & Mean & SD & \\
\hline Fruits and vegetables & $\geq 500 \mathrm{~g} / \mathrm{d}$ & 502 & 245 & 519 & 240 & 0.730 & 561 & 198 & 441 & 213 & 0.002 \\
\hline Fruits & & 242 & 183 & 243 & 217 & 0.970 & 276 & 144 & 235 & 174 & 0.161 \\
\hline Vegetables & & 260 & 115 & 276 & 122 & 0.476 & 285 & 108 & 205 & 100 & $<0.001$ \\
\hline Whole grains & $70-90 \mathrm{~g} / \mathrm{d}$ & 59 & 31 & 50 & 24 & 0.076 & 63 & 24 & 49 & 16 & $<0.001$ \\
\hline Red meat & $<500 \mathrm{~g} /$ week & 94 & 45 & 89 & 46 & 0.547 & 63 & 26 & 53 & 31 & 0.065 \\
\hline Fish & $300-450 \mathrm{~g} /$ week & 84 & 60 & 71 & 56 & 0.237 & 72 & 50 & 56 & 40 & 0.051 \\
\hline Dairy products & & 452 & 404 & 431 & 349 & 0.759 & 342 & 217 & 266 & 228 & 0.059 \\
\hline Yoghurt & & 56 & 12 & 43 & 73 & 0.422 & 98 & 97 & 43 & 66 & 0.001 \\
\hline Nuts & $140 \mathrm{~g} /$ week & 9 & 15 & 9 & 20 & 0.994 & 7 & 8 & 8 & 11 & 0.529 \\
\hline
\end{tabular}

${ }^{*}$ Means were compared by $t$ tests.

†Norwegian Food-based Dietary Guidelines ${ }^{(20)}$. 


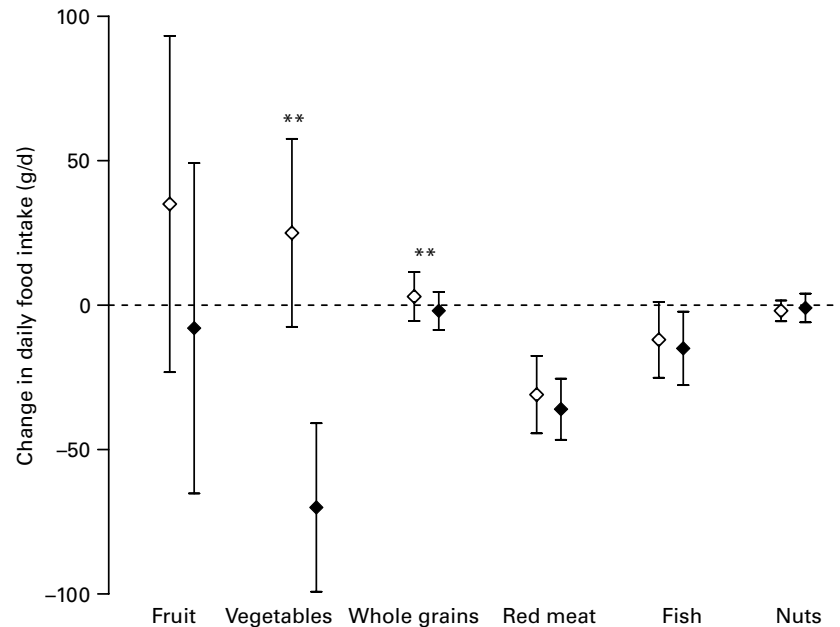

Fig. 2. Within-group changes, mean $(95 \% \mathrm{Cl})$, in daily intakes of selected food groups in morbidly obese patients at 1 year after start of either intensive lifestyle intervention $(\diamond)$ or gastric bypass surgery $(\diamond)$. The statistical significance of various between-group differences are calculated with the use of ANCOVA. Between-group differences were adjusted for sex, age, baseline $\mathrm{BMI}$ and baseline values of the dependent variables. ${ }^{* *}$ Mean values were significantly different $(P<0.001)$.

The intake of added sugar decreased significantly only in the lifestyle group, with no significant between-group difference $(P=0.598)$

The surgery group had a significantly larger decrease in fibre intake than the lifestyle group (data not shown in figure, between-group difference, $P<0.001$ )

\section{Discussion}

In the present 1-year non-randomised controlled trial, we have shown that morbidly obese patients who participated in a comprehensive lifestyle intervention programme with intermittent stays at a rehabilitation centre reported more favourable changes in their dietary pattern according to present guidelines compared with patients who underwent gastric bypass surgery. At follow-up, the lifestyle group had a greater intake $(\mathrm{g} / \mathrm{d})$ of fruits and vegetables, whole grains and fibre and a lower intake (percentage of total energy) of total, saturated and monounsaturated fat than the surgery group.

To the best of our knowledge, only two case-control studies of obese subjects (both from the National Weight Control Registry) have compared nutrient intake between patients achieving significant weight loss through either surgical or non-surgical methods ${ }^{(32,33)}$. As in the present study, the surgical group reported a significantly higher intake of fat (37 $v$. $35 \%$ in the present study) than the non-surgical group (28 $\mathrm{v}$. $31 \%)^{(33)}$. However, the study designs in these studies were cross-sectional and did not include changes in nutrient intake or details on various food groups. In addition, intake of fibre and saturated fat was not assessed. The surgical participants in the National Weight Control Registry database reported less physical activity than the non-surgical participants ${ }^{(33)}$, which is consistent with previously published findings from the present study ${ }^{(27)}$.

Although few studies have examined food intake patterns after surgical weight loss, changes in the percentage intake of macronutrients after bariatric surgery have been explored to a limited extent. In one study, women who underwent gastric bypass surgery and visited a registered dietitian four times during the first post-operative year had a similar distribution of macronutrients at baseline and at the end of follow-up ( $41 \%$ of energy from carbohydrates, $41 \%$ from fat and $15 \%$ from protein $)^{(23)}$. Similarly, a study comparing two surgical methods showed no significant changes in the percentage intake of fat from the time of gastric bypass surgery up to 1 year follow-up $(41 \% \text {, twenty-six women })^{(22)}$. In contrast, Olbers et al. have demonstrated that patients randomised to gastric bypass

Table 3. Daily intake of energy-yielding nutrients at baseline and changes after start of either intensive lifestyle intervention or gastric bypass surgery

(Mean values and standard deviations)

\begin{tabular}{|c|c|c|c|c|c|c|c|c|c|c|c|}
\hline \multirow[b]{3}{*}{ Nutrient } & \multirow[b]{3}{*}{$\mathrm{RDI}^{(32)}$} & \multicolumn{5}{|c|}{ Baseline } & \multicolumn{5}{|c|}{ 1-year follow-up } \\
\hline & & \multicolumn{2}{|c|}{$\begin{array}{l}\text { Lifestyle } \\
\quad(n 54)\end{array}$} & \multicolumn{2}{|c|}{$\begin{array}{c}\text { Surgery } \\
(n 72)\end{array}$} & \multirow[b]{2}{*}{$P^{*}$} & \multicolumn{2}{|c|}{$\begin{array}{c}\text { Lifestyle } \\
\text { (n 54) }\end{array}$} & \multicolumn{2}{|c|}{$\begin{array}{c}\text { Surgery } \\
(n 72)\end{array}$} & \multirow[b]{2}{*}{$P^{*}$} \\
\hline & & Mean & SD & Mean & SD & & Mean & SD & Mean & $\mathrm{SD}$ & \\
\hline \multicolumn{12}{|l|}{ Energy } \\
\hline MJ & $9.2-11.8 \dagger$ & $12 \cdot 0$ & $3 \cdot 8$ & 11.5 & $5 \cdot 0$ & 0.527 & 8.5 & $2 \cdot 0$ & 6.9 & $1 \cdot 8$ & $<0.001$ \\
\hline kcal & & 2869 & 914 & 2746 & 1185 & 0.527 & 2032 & 483 & 1650 & 435 & $<0.001$ \\
\hline Protein (E\%) & $10-20$ & 17 & 3 & 17 & 3 & 0.910 & 20 & 3 & 19 & 3 & 0.628 \\
\hline Total fat (E\%) & $<30$ & 38 & 6 & 37 & 6 & 0.760 & 31 & 6 & 35 & 6 & $<0.001$ \\
\hline SFA & $<10$ & 15 & 3 & 15 & 3 & 0.777 & 12 & 3 & 14 & 3 & $<0.001$ \\
\hline MUFA & $10-15$ & 13 & 2 & 13 & 2 & 0.835 & 11 & 2 & 12 & 2 & $<0.001$ \\
\hline PUFA & $5-10$ & 8 & 3 & 7 & 2 & 0.249 & 6 & 2 & 7 & 2 & 0.177 \\
\hline $\mathrm{CHO}(\mathrm{E} \%)$ & $50-60$ & 45 & 6 & 45 & 7 & 0.688 & 48 & 6 & 44 & 6 & $<0.001$ \\
\hline Sugar & $<10$ & 7 & 5 & 7 & 7 & 0.716 & 5 & 3 & 5 & 4 & 0.448 \\
\hline Fibre (g) & $\geq 25$ & 29 & 9 & 29 & 11 & 0.939 & 28 & 6 & 22 & 6 & $<0.001$ \\
\hline
\end{tabular}

$\mathrm{RDI}$, recommended daily intake; $\mathrm{E} \%$, percentage of energy; $\mathrm{CHO}$, carbohydrates.

${ }^{*}$ Means were compared by $t$ tests.

† The individual mean RDI is dependent on sex, age and physical activity level. For normal-weight individuals $\left(\mathrm{BMI} 18.5-25 \mathrm{~kg} / \mathrm{m}^{2}\right)$ aged $31-60$ years, with a sedentary lifestyle, energy intake reference is $11.8 \mathrm{MJ} / \mathrm{d}$ for men and $9.2 \mathrm{MJ} / \mathrm{d}$ for women. 


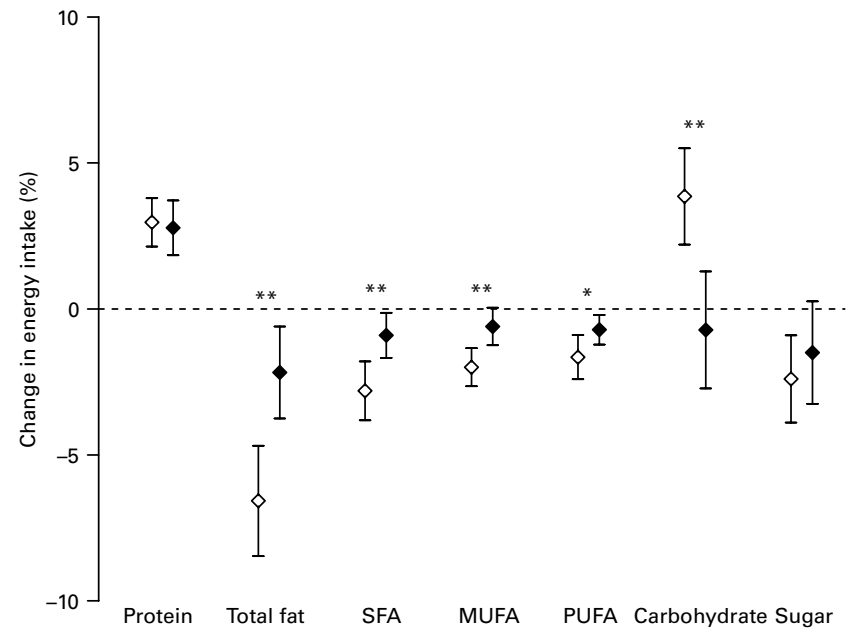

Fig. 3. Within-group changes, mean $(95 \% \mathrm{Cl})$, in intake of energy-yielding nutrients in morbidly obese patients from baseline to 1 year after start of either intensive lifestyle intervention $(\diamond)$ or gastric bypass surgery $(\diamond)$. The statistical significance of various between-group differences are calculated with the use of ANCOVA. Between-group differences were adjusted for sex, age, baseline BMI and baseline values of the dependent variables. Mean values were significantly different: ${ }^{\star} P<0.05,{ }^{\star \star} P<0.001$.

reported a significant reduction in percentage fat intake, from 34.4 to $30.5 \%$ at 1 year after surgery. In contrast with the former studies and in partial agreement with the latter, we found a small reduction in percentage intake of fat in the surgery group (37-35\%). Direct comparison with the present study is, however, difficult, given that no information regarding dietary recommendations was reported in these studies. Furthermore, the relative percentages of saturated, monoand polyunsaturated fat were not assessed in these studies $^{(22-24)}$. At baseline, the majority of our patients did not adhere to the recommended intake of saturated fat $(<10 \% \text { of energy })^{(31)}$. The proportion of patients adhering to this recommendation at follow-up was significantly higher in the lifestyle group (22\%) than in the surgery group (4\%).

An interesting finding was that both intervention groups reduced their fish intake, even though increased fish intake is recommended in both intervention programmes and healthy diet advice for the population in general ${ }^{(20)}$. Furthermore, in spite of gastric bypass patients being advised to eat low-fat dairy products as a source of protein, they showed a marked reduction in dairy product intake after 1 year. Even though surgically treated patients may experience varying degrees of food intolerance (dumping, nausea) in the first post-operative months, which may limit the food type and amount consumed, the degree of malaise is highly individual, with patients tending to return to a more 'normal' diet after this period ${ }^{(34,35)}$. As fish and yoghurt are nutritious, proteinrich foods recommended after bariatric surgery, one might have expected that consumption of these foods would be higher in the surgery group.

Both groups decreased their intake of red meat, with a greater decrease in the surgery group than the lifestyle group. This difference may be related to the fact that the surgically treated patients were informed that whole meat could cause discomfort in the initial weeks after operation because of its tough, dry texture ${ }^{(36)}$.

Even though patients in both intervention groups were advised to maintain a healthy diet, only patients in the lifestyle group increased intake of fruits, vegetables and whole grains in accordance with recent $\mathrm{FBDG}^{(19,20)}$. No previous studies have assessed changes in intake of whole grains after bariatric surgery, while avoidance of fruits and vegetables has been reported among $10 \%$ of patients at 1 year after gastric bypass surgery ${ }^{(24)}$. Even though patients treated with gastric bypass surgery may be able to eat all kinds of foods at 1 year after intervention ${ }^{(24)}$, the present findings support previous studies indicating that patients undergoing bariatric surgery report a persistent unfavourable dietary pattern ${ }^{(22,23)}$.

\section{Limitations}

The strengths of the present study include the prospective design, the homogeneous dietary characteristics of the intervention groups and its extensive dietary registration using a validated FFQ. The study also has its limitations. As a result of the non-randomised design, there is a risk of treatment allocation bias. Shorter intervention delay in the lifestyle group may have affected the participants' motivation and willingness to implement and maintain beneficial dietary changes ${ }^{(27)}$. Moreover, the intense dietary counselling and support given to the lifestyle group may have improved dietary compliance relative to the surgery group.

The use of FFQ helped standardise the reported food consumption, but we did not use biomarkers to compare the given information.

Although age and weight differences in the treatment groups were adjusted for in the multivariate analyses (ANCOVA), they might have biased the present findings. In addition, we cannot exclude the possibility that unknown confounders such as behavioural characteristics and genetics might have influenced the present results. To avoid discomfort post-operatively, the surgery patients were advised to avoid certain types of fruits and vegetables for 4-8 weeks. Possibly, this may have affected food choice over a longer time period. Further, dietary reporting error is a known source of bias in studies including obese individuals ${ }^{(37)}$. Dietary assessment methods based on recall, such as FFQ, are susceptible to reporting bias due to both inaccurate recall and social desirability. Such tendencies may affect the reported accuracy of type and amount of what has actually been eaten. However, reporting bias among participants would need to be differentially distributed among those treated with surgery and lifestyle treatment to appreciably influence the between-group differences presented here. The FFQ method has also been shown to capture more realistic energy intake and distribution in obese individuals than $24 \mathrm{~h}$ dietary recalls ${ }^{(37)}$.

Information on eating disorders was not available in either group. We have described dietary changes during a relatively short time period (1 year); whether the results achieved will persist in the long term remains to be seen. Finally, the majority of participants were of European origin, and as 
such the results may not necessarily be valid in other ethnic or cultural settings.

\section{Conclusion}

Morbidly obese Caucasian patients who underwent an intensive lifestyle intervention programme with intermittent stays at a rehabilitation centre reported more favourable dietary changes than patients who underwent gastric bypass surgery at 1 year after the start of the intervention. The hypothesis that a persistent unfavourable dietary pattern may counteract the well-established long-term beneficial health effects of bariatric surgery needs to be addressed in future studies.

When preparing future nutritional guidelines for patients undergoing bariatric surgery, one should consider emphasising the importance of dietary improvement with focus not only on energy balance, but also on dietary composition and quality.

\section{Acknowledgements}

We thank Beate T. Oppedal, Marthe B. Fevang and Heidi O. Fon for their help in collecting data; Linda Mathisen for organising patient logistics; Berit M. Bjørkås for help with managing the study database; Jannicke Borch Myhre for assistance with processing the FFQ; and Matthew McGee for proofreading the manuscript. L. K. J. was supported by a research fellowship grant from the Norwegian Resource Center for Women's Health, Oslo University Hospital Rikshospitalet. None of the authors report a personal or financial conflict of interest. L. K. J., D. H., R. S. and J. H. designed the research; D. H., R. S. and L. K. J. conducted the research; L. K. J. performed statistical analyses; L. K. J., J. H. and J. R. analysed the data; L. K. J. and J. H. wrote the paper; and J. H. had primary responsibility for final content. All authors helped interpret the data, revise the manuscript and approve the final version.

\section{References}

1. Renehan AG, Tyson M, Egger M, et al. (2008) Body-mass index and incidence of cancer: a systematic review and meta-analysis of prospective observational studies. Lancet 371, 569-578.

2. Flegal KM, Graubard BI, Williamson DF, et al. (2007) Cause-specific excess deaths associated with underweight, overweight, and obesity. JAMA 298, 2028-2037.

3. Jia H \& Lubetkin EI (2005) The impact of obesity on healthrelated quality-of-life in the general adult US population. J Public Health (Oxf) 27, 156-164.

4. Berrington de GA, Hartge P, Cerhan JR, et al. (2010) Body-mass index and mortality among 1.46 million white adults. $N$ Engl J Med 363, 2211-2219.

5. Sjostrom L, Narbro K, Sjostrom CD, et al. (2007) Effects of bariatric surgery on mortality in Swedish obese subjects. $N$ Engl J Med 357, 741-752.

6. Adams TD, Gress RE, Smith SC, et al. (2007) Long-term mortality after gastric bypass surgery. N Engl J Med 357, 753-761.
7. Sjostrom L, Gummesson A, Sjostrom CD, et al. (2009) Effects of bariatric surgery on cancer incidence in obese patients in Sweden (Swedish Obese Subjects Study): a prospective, controlled intervention trial. Lancet Oncol 10, 653-662.

8. Dansinger ML, Gleason JA, Griffith JL, et al. (2005) Comparison of the Atkins, Ornish, Weight Watchers, and Zone diets for weight loss and heart disease risk reduction: a randomized trial. JAMA 293, 43-53.

9. Dyson PA (2010) The therapeutics of lifestyle management on obesity. Diabetes Obes Metab 12, 941-946.

10. Sacks FM, Bray GA, Carey VJ, et al. (2009) Comparison of weight-loss diets with different compositions of fat, protein, and carbohydrates. $N$ Engl J Med 360, 859-873.

11. Mozaffarian D, Hao T, Rimm EB, et al. (2011) Changes in diet and lifestyle and long-term weight gain in women and men. $N$ Engl J Med 364, 2392-2404.

12. Goldstein LB, Adams R, Alberts MJ, et al. (2006) Primary prevention of ischemic stroke: a guideline from the American Heart Association/American Stroke Association Stroke Council: cosponsored by the Atherosclerotic Peripheral Vascular Disease Interdisciplinary Working Group; Cardiovascular Nursing Council; Clinical Cardiology Council; Nutrition, Physical Activity, and Metabolism Council; and the Quality of Care and Outcomes Research Interdisciplinary Working Group. Circulation 113, e873-e923.

13. Van HL, McCoin M, Kris-Etherton PM, et al. (2008) The evidence for dietary prevention and treatment of cardiovascular disease. J Am Diet Assoc 108, 287-331.

14. Thompson R (2010) Preventing cancer: the role of food, nutrition and physical activity. J Fam Health Care 20, 100-102.

15. World Cancer Research Fund/American Institute for Cancer Research (2007) Food, Nutrition, Physical Activity, and the Prevention of Cancer: A Global Perspective. Second Expert Report. Washington, DC: AICR.

16. Pan A, Sun Q, Bernstein AM, et al. (2012) Red meat consumption and mortality: results from 2 prospective cohort studies. Arch Intern Med 172, 555-563.

17. Bantle JP, Wylie-Rosett J, Albright AL, et al. (2008) Nutrition recommendations and interventions for diabetes: a position statement of the American Diabetes Association. Diabetes Care 31, Suppl. 1, S61-S78.

18. Mann JI, De Leeuw I, Hermansen K, et al. (2004) Evidencebased nutritional approaches to the treatment and prevention of diabetes mellitus. Nutr Metab Cardiovasc Dis 14, 373-394.

19. U.S. Department of Agriculture \& U.S. Department of Health and Human Services (2010) Dietary Guidelines for Americans, 2010, 7th ed. Washington, DC: U.S. Government Printing Office.

20. Nasjonalt råd for ernæring. (2011) Kostråd for å fremme folkehelsen og forebygge kroniske sykdommer: metodologi og vitenskapelig kunnskapsgrunnlag (Dietary Advice for Promoting Public Health and Preventing Chronic Diseases: Methodology and Scientific Knowledge). Oslo: Helsedirektoratet.

21. Martins C, Strommen M, Stavne OA, et al. (2011) Bariatric surgery versus lifestyle interventions for morbid obesitychanges in body weight, risk factors and comorbidities at 1 year. Obes Surg 21, 841-849.

22. Näslund I, Järnmark I \& Andersson H (1988) Dietary intake before and after gastric bypass and gastroplasty for morbid obesity in women. Int J Obes 12, 503-513.

23. Kruseman M, Leimgruber A, Zumbach F, et al. (2010) Dietary, weight, and psychological changes among patients with obesity, 8 years after gastric bypass. J Am Diet Assoc 110, $527-534$. 
24. Olbers T, Bjorkman S, Lindroos A, et al. (2006) Body composition, dietary intake, and energy expenditure after laparoscopic Roux-en-Y gastric bypass and laparoscopic vertical banded gastroplasty: a randomized clinical trial. Ann Surg 244, 715-722.

25. Finucane MM, Stevens GA, Cowan MJ, et al. (2011) National, regional, and global trends in body-mass index since 1980 systematic analysis of health examination surveys and epidemiological studies with 960 country-years and $9 \cdot 1$ million participants. Lancet 377, 557-567.

26. Hofso D, Jenssen T, Bollerslev J, et al. (2009) Anthropometric characteristics and type 2 diabetes in extremely obese Caucasian subjects: a cross-sectional study. Diabetes Res Clin Pract 86, e9-e11.

27. Hofso D, Nordstrand N, Johnson LK, et al. (2010) Obesityrelated cardiovascular risk factors after weight loss: a clinical trial comparing gastric bypass surgery and intensive lifestyle intervention. Eur J Endocrinol 163, 735-745.

28. Andersen LF, Solvoll K, Johansson LR, et al. (1999) Evaluation of a food frequency questionnaire with weighed records, fatty acids, and alpha-tocopherol in adipose tissue and serum. Am J Epidemiol 150, 75-87.

29. Nes M, Frost AL, Solvoll K, et al. (1992) Accuracy of a quantitative food frequency questionnaire applied in elderly Norwegian women. Eur J Clin Nutr 46, 809-821.
30. Aasheim ET, Johnson LK, Hofso D, et al. (2011) Vitamin status after gastric bypass and lifestyle intervention: a comparative prospective study. Surg Obes Relat Dis 8, 169-175.

31. Nordic Council of Ministers (2004) Nordic Nutrition Recommendations 2004: Integrating Nutrition and Physical Activity, 4th ed. Copenhagen: Nordisk Ministerråd.

32. Klem ML, Wing RR, Chang CC, et al. (2000) A case-control study of successful maintenance of a substantial weight loss: individuals who lost weight through surgery versus those who lost weight through non-surgical means. Int $J$ Obes Relat Metab Disord 24, 573-579.

33. Bond DS, Phelan S, Leahey TM, et al. (2009) Weight-loss maintenance in successful weight losers: surgical vs nonsurgical methods. Int J Obes 33, 173-180.

34. Thomas JR, Gizis F \& Marcus E (2010) Food selections of Roux-en-Y gastric bypass patients up to 2.5 years postsurgery. J Am Diet Assoc 110, 608-612.

35. Fujioka K (2005) Follow-up of nutritional and metabolic problems after bariatric surgery. Diabetes Care 28, 481-484.

36. Aills L, Blankenship J, Buffington C, et al. (2008) ASMBS allied health nutritional guidelines for the surgical weight loss patient. Surg Obes Relat Dis 4, S73-S108.

37. Lissner L, Troiano RP, Midthune D, et al. (2007) OPEN about obesity: recovery biomarkers, dietary reporting errors and BMI. Int J Obes (Lond) 31, 956-961. 